\section{References}

Connolly, N., and Godfrey, S. (1970). Assessment of the child with asthma. Journal of Asthma Research, 8, 31-36.

Godfrey, S., and König, P. (1974). Treatment of childhood asthma for thirteen months and longer with beclomethasone dipropionate aerosol. Archives of Disease in Childhood, 49, 591-596.

Hallworth, G. W. (1977). An improved design of powder inhaler. British Journal of Clinical Pharmacology, 4, 689690.

Lovera, J., Cooper, D. M., Collins-Williams, C., Levison, H.,
Bailey, J. D., and Orange, R. P. (1976). Clinical and physiological assessment of asthmatic children treated with beclomethasone dipropionate. Journal of Allergy and Clinical Immunology, 57, 112-113.

Morrow Brown, H., and Storey, G. (1973). Beclomethasone dipropionate steroid aerosol in the treatment of perennial allergic asthma in children. British Medical Journal, 3, 161-164.

Correspondence to Dr A. T. Edmunds, Department of Child Health, Royal Hospital for Sick Children, St Michael's Hill, Bristol BS2 8BJ.

\title{
Cefuroxime plasma and CSF levels in children with meningitis
}

\author{
J. A. KUZEMKO AND S. R. WALKER
}

Paediatric Department, Peterborough District Hospital, and Glaxo Research Limited, Clinical Division, Greenford, Middlesex

SUMMARY Cefuroxime $(25 \mathrm{mg} / \mathrm{kg})$ given intravenously every four hours to 7 children with bacterial meningitis resulted in satisfactory therapeutic blood and CSF levels. All children made a full recovery and side effects were absent.

Bacterial meningitis in children carries a $10-15 \%$ mortality rate and there can be significant neurological damage in children who recover (Goldacre, 1977). The success of any antibiotic in the treatment of this disease depends on its antibacterial properties and the concentration that remains in the blood and CSF after systemic administration. Unfortunately, during the last few years, sulphonamide-resistant meningcocci have emerged (Lambert, 1974), Haemophilus influenzae is now sometimes resistant to ampicillin because of $\beta$-lactamase production, and meningitis due to chloramphanicol-resistant $H$. influenzae has recently been reported (Kinmonth et al., 1978). Therefore, triple treatment with a sulphonamide, ampicillin, and chloramphenicol is often used before the causative organism is known. Cefuroxime, unlike the other three agents, is highly active against all the organisms that commonly cause meningitis-namely Neisseria meningitidis, $H$. influenzae, and Streptococcus pneumoniae (O’Callaghan et al., 1976). It was felt appropriate, therefore, to determine blood and CSF levels of cefuroxime in children with meningitis before this antibiotic was considered as an alternative treatment.

\section{Patients, methods, and results}

The treatment currently used at this hospital for children with meningitis consists of ampicillin ( $25 \mathrm{mg} / \mathrm{kg}$ ), chloramphenicol ( $15 \mathrm{mg} / \mathrm{kg}$ ), and sulphadimidine $(25 \mathrm{mg} / \mathrm{kg})$, by IV infusion every four hours for a period of up to 5 days. Treatment is modified depending on the sensitivity of the organism to these agents, and then it is continued orally for an additional period of 5 days.

Cefuroxime $(25 \mathrm{mg} / \mathrm{kg})$ was given intravenously by a 20-minute infusion every four hours to 7 children ( 6 boys; age range, $1 \frac{1}{2}-6$ years) for periods of between one and 5 days in addition to the above treatment. The organism responsible for the meningitis in 3 children was $N$. meningitidis (all resistant to sulphadimidine), and in the other 4 it was $H$. influenzae. Sensitivity testing showed that all the isolated organisms were highly sensitive to cefuroxime. Blood samples were taken twice during treatment and plasma levels of cefuroxime were determined between 30 and $90 \mathrm{~min}$ and 4 hours after injection. CSF levels of cefuroxime were measured in 3 patients in whom lumbar punctures were clinically indicated; one child with CSF pressure had lumbar punctures performed 2 hours after a cefuroxime injection on 4 consecutive days. All samples were analysed by a high-pressure liquid chromatography method which enabled cefuroxime to be determined in the presence of other drugs.

Plasma levels of cefuroxime (Figure) determined at between 30 and 90 min and 4 hours after IV infusion 




Figure Plasma levels of cefuroxime in children with meningitis.

showed that adequate blood levels were obtained and maintained throughout the treatment period. In 3 children the concentration of cefuroxime in
CSF was determined and found to be between 1.5 and $9 \mu \mathrm{g} / \mathrm{ml}$.

\section{Comment}

Satisfactory therapeutic blood and CSF levels of cefuroxime are obtained in children with bacterial meningitis, if a dose of $25 \mathrm{mg} / \mathrm{kg}$ is given by IV infusion every 4 hours. CSF levels were several times is higher than the MICs for $N$. meningitidis $(0.025 \mu \mathrm{g} / \overrightarrow{\mathrm{\sigma}}$ $\mathrm{ml})$ and $H$. influenzae $(0.5 \mu \mathrm{g} / \mathrm{ml})$. No toxic side effect was noted and all the children made a good recovery. Although one patient was treated successfully with cefuroxime alone after the first day on triple therapy, further clinical studies with cefuroxime are needed to determine whether this new cephalosporin should become a first-line treatment of bacterial meningitis.

We thank Mr John Ayrton of Glaxo Research Limited for the cefuroxime analyses.

\section{References}

Goldacre, M. J. (1977). Acute bacterial meningitis in childhood: aspects of prehospital care in 687 cases. Archives of Disease in Childhood, 52, 501-503.

Kinmonth, A-L., Storrs, C. N., and Mitchell, R. G. (1978). Meningitis due to chloramphenicol-resistant Haemophilus influenzae type b. British Medical Journal, 1, 694.

Lambert, H. P. (1974). Acute meningitis. British Journal of Hospital Medicine, 268-274.

O'Callaghan, C. H., Sykes, R. B., Ryan, D. M., Foord, R. D., and Muggleton, P. W. (1976). Cefuroxime-a new cephalosporin antibiotic. Journal of Antibiotics, 29, 29-37.

Correspondence to Dr J. A. Kuzemko, Peterborough District Hospital, Thorpe Road, Peterborough PE3 6DA.

\title{
Idiopathic hypoparathyroidism with extrapyramidal and myopathic features
}

\author{
R. O. WALTERS \\ The Hospital for Sick Children, Great Ormond Street, London
}

SUMMARY A case of idiopathic hypoparathyroidism and basal ganglia calcification with extrapyramidal motor and myopathic features is described. The extrapyramidal motor and myopathic features disappeared when normocalcaemia was restored with treatment, suggesting that they resulted from hypocalcaemia.
Idiopathic hypoparathyroidism is an uncommon disease of childhood in which the typical neuromuscular disorders are tetany, fits, and mental retardation. Extrapyramidal and myopathic features have only rarely been described.

\section{Case report}

A 12-year-old boy presented with a 2-year history of 